\title{
zans Research Square \\ Synthesis of Iridium-Based Nanocomposites With Catalase Activity For Cancer PTT/PDT Therapy
}

\section{Hang Wu}

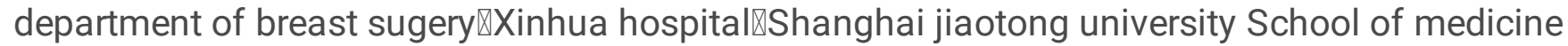

\section{Qi Jiang}

Changhai Hospital Department of Gastroenterology

\section{Keyi Luo}

college of science,university of shanghai for science and technology

Chunping Zhu

Changhai Hospital Department of Gastroenterology

\section{Mengmeng Xie}

College of Science, University of Shanghai for Science and Technology

\section{Shige Wang}

College of Science, University of Shanghai for Science and Technology

\section{Zhewei Fei}

department of breast surgery,Xinhua hospitial,shanghai jiaotong university school of medicine

Jiulong Zhao ( jlzhao9@163.com)

Changhai Hospital Department of Gastroenterology

\section{Research}

Keywords: Photothermal therapy, Photodynamic therapy, Cancer treatment, Biocompatibility, Iridium nanocomposite

Posted Date: April 6th, 2021

DOI: https://doi.org/10.21203/rs.3.rs-375111/v1

License: (c) (i) This work is licensed under a Creative Commons Attribution 4.0 International License.

Read Full License

Version of Record: A version of this preprint was published at Journal of Nanobiotechnology on July 7th, 2021. See the published version at https://doi.org/10.1186/s12951-021-00948-8. 


\section{Abstract}

The combination of photothermal therapy (PTT) and photodynamic therapy (PDT) has attracted attention due to its enhanced tumor synergetic effect. This study proposes a novel nanoenzyme-based theranostic nanoplatform, IrO ${ }_{2} @ M S N @ P D A-B S A(C e 6)$, for the combined PTT and PDT of tumors. IrO 2 was prepared by a simple hydrolysis method and coated with a thin layer of mesoporous silica (MSN) to facilitate the physical adsorption of Chlorin e6 (Ce6). The PDA coating and $\mathrm{IrO}_{2} \mathrm{NPs}$ of the nanoplatform demonstrated an improved photothermal conversion efficiency of $29.8 \%$ under NIR irradiation. Further, the Ce6 loading imparts materials with the ability to produce reactive oxygen species (ROS) under 660 $\mathrm{nm}$ NIR laser irradiation. It was also proved that the $\mathrm{IrO}_{2} \mathrm{NPs}$ could catalyze the hydrogen peroxide $\left(\mathrm{H}_{2} \mathrm{O}_{2}\right)$ in the tumor microenvironment (TME) to generate endogenous oxygen $\left(\mathrm{O}_{2}\right)$, thereby enhancing the efficiency of PDT. The in vitro and in vivo experiments indicated that the nanocomposites were highly biocompatible and could produce a satisfactory tumor therapeutic effect. Thus, the findings of the present study demonstrate the viability of using theranostic nanoenzymes for translational medicine.

\section{Introduction}

Cancer is currently one of the major obstacles preventing the reduction of the global mortality rate[1, 2]. Traditional cancer treatment strategies, such as chemotherapy, radiation therapy, and surgery, result in unavoidable side effects, the development of drug resistance, and ineligibility for surgery [3-5]. The limitations of these treatments have motivated researchers to develop new cancer treatments with relatively few side effects and a high efficiency. Near-infrared light (NIR)-induced tumor therapies, such as photothermal therapy (PTT) and photodynamic therapy (PDT), have attracted the attention of many researchers because they are highly effective, non-invasive, spatiotemporally controllable, and lead to relatively few side effects $[6,7]$.

PDT involves the absorption of photon energy by a photosensitizing agent (PSA), resulting in the transfer of its electrons to the oxygen molecules $\left(\mathrm{O}_{2}\right)$ in the cancer cells. This leads to the production of a highly toxic reactive oxygen species (ROS, e.g., ${ }^{1} \mathrm{O}_{2}$ ) that cause irreparable damage to the cancer cells [8]. A light operative dose, reasonable PSA concentration, and adequate oxygen are necessary for effective tumor ablation. In addition, the amount of $\mathrm{O}_{2}$ directly affects the efficiency of PDT [9]. Due to the rapid and uncontrolled proliferation of tumor cells, the $\mathrm{O}_{2}$ levels in solid tumors are inadequate, thereby reducing the therapeutic efficiency of PDT $[10,11]$. Thus, researchers have proposed innovative strategies to enhance the $\mathrm{O}_{2}$ concentration in tumors [12]. Oxygen carriers, such as perfluorocarbon (PFC) nanoparticles NPs, can facilitate continuous oxygen supply and have been used to enhance the $\mathrm{O}_{2}$ concentration in tumors for PDT [13]. Enzyme-like substances with catalase activity have recently been used with PSA to counter hypoxia and enable ROS generation [14]. Researchers have discovered that the overexpression of $\mathrm{H}_{2} \mathrm{O}_{2}$ in a tumor microenvironment (TME) can be utilized for the catalytic generation of endogenous $\mathrm{O}_{2}$ and facilitate tumor PDT $[15,16]$. Nanoenzymes, in comparison with natural catalase, have a relatively low 
cost, high activity, and qualified thermostability. Therefore, they can be employed to enhance the therapeutic effect of PDT [17-19].

PTT is an alternative phototherapy technique that can utilize the photothermal effects of photothermal transduction agents (PTAs) to raise the temperature of the surrounding environment and trigger the ablation and apoptosis of cancer cells $[20,21]$. The application of a PTA with high biocompatibility and efficient photothermal conversion efficiency is likely to improve the efficiency of photothermal therapy [22]. Several PTAs, such as two-dimensional (2D) materials [23], noble metal materials [24], metal chalcogenide materials [25], and conjugated polymers (e.g., polydopamine (PDA) and polypyrrole (PPy)), have been synthesized in recent years [26, 27]. However, owing to the poor performance of a single PTA, high-energy NIR laser irradiation or a relatively strong dose of PTA is required to obtain the desired treatment effect[28]. In addition, it is difficult to achieve satisfactory therapeutic activity by solely using PTT[29]. Thus, modern studies are focusing on dual-mode therapy combinations of PTT and PDT [30, 31]. The main obstacle involves building a reasonable nanoplatform to maximize the synergistic effects of PTT and PDT to kill tumor cells.

The application of iridium oxide $\left(\mathrm{IrO}_{2}\right)$ has recently drawn attention due to its high biocompatibility and photothermal conversion efficiency [32]. Studies have discovered that $\mathrm{IrO}_{2}$ has catalase (CAT)-like activity that enables it to catalyze $\mathrm{H}_{2} \mathrm{O}_{2}$ in the TME to generate endogenous $\mathrm{O}_{2}$, thereby enhancing the efficiency of PDT [33]. However, few studies have utilized $\mathrm{IrO}_{2}$ nanomaterial-based nanoplatform systems for the combined PTT and PDT treatment of tumors.An IrO ${ }_{2} @ M S N @ P D A-B S A$ nanocomposite was synthesized in this study for the PTT and PDT dual-mode therapeutic treatment of tumors. IrO $\mathrm{I}_{2}$ was prepared by a simple hydrolysis method and coated with a thin layer of mesoporous silica (MSN) to facilitate the physical adsorption of Chlorin e6 (Ce6). Subsequently, PDA was coated on the surface of $\mathrm{IrO}_{2} @ M S N$, followed by the grafting of bovine serum albumin (BSA) on the surface of $1 \mathrm{rO}_{2} @ \mathrm{MSN} @ P D A$ as a stabilizer. The installation of $\mathrm{Ir}_{2} @ M S N @ P D A-B S A(\mathrm{Ce} 6)$ serves several purposes. The PDA coating and $\mathrm{IrO}_{2}$ NPs demonstrate significant photothermal conversion under NIR irradiation. Ir ${ }_{2} @ M S N @ P D A-$ $\mathrm{BSA}(\mathrm{Ce} 6)$ can produce ROS to kill cancer cells under photon activation. $\mathrm{IrO}_{2}$ can also catalyze the decomposition of $\mathrm{H}_{2} \mathrm{O}_{2}$ to enhance the production of $\mathrm{O}_{2}$ in the TME, thereby enhancing the therapeutic effect of PDT. In vitro and in vivo experiments have proved that IrO ${ }_{2} @ M S N @ P D A-B S A(C e 6)$ is biocompatible and can passively target tumors through the enhanced permeability and retention (EPR) effect, thereby harnessing the clinical and synergistic effects of PTT and PDT for the tumors. The design of $\mathrm{IrO}_{2} @ M S N @ P D A-B S A(\mathrm{Ce} 6)$ provides a framework for the design of multifunctional nanocomposites that can accurately treat cancer.

\section{Experimental Section}

\subsection{Preparation and characterization of $\mathrm{IrO}_{2} @ M S N @ P D A-$ BSA and the loading of $\mathrm{Ce} 6$}




\subsubsection{Synthesis of $\mathrm{IrO}_{2}-\mathrm{PVP}$ NPs}

For the synthesis of $\mathrm{IrO}_{2}$-PVP nanoparticles, first, $0.05 \mathrm{~g} \mathrm{IrCl}_{3}$ and $0.1 \mathrm{~g} \mathrm{PVP}$ were dissolved in $15 \mathrm{~mL}$ of distilled water by magnetic stirring $(400 \mathrm{rpm})$ at room temperature. Then, the solution $\mathrm{pH}$ was adjusted to 12 using $\mathrm{NaOH}$ solution $(2.0 \mathrm{M})$, and the mixture was allowed to react at $80^{\circ} \mathrm{C}$ for 12 hours with stirring. Finally, the mixture was further separated by centrifugation (12000 rpm, $5 \mathrm{~min}$ ), and then rinsed three times with ethanol and distilled water. The sample in this experiment was freeze-dried and collected for the following usages.

\subsubsection{Synthesis of $\mathrm{IrO}_{2} @ M S N$ NPs}

For the synthesis of $\mathrm{IrO}_{2} @ M S N$ nanoparticles, the as-prepared $\mathrm{IrO}_{2}$-PVP NPs were dissolved in $65 \mathrm{~mL}$

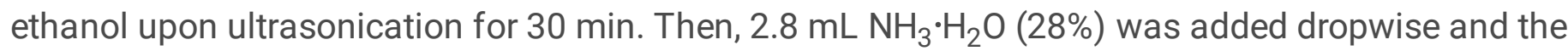
mixture was stirred at room temperature for 30 minutes. Subsequently, $0.1 \mathrm{~mL}$ TEOS was dissolved in 6.5 $\mathrm{mL}$ ethanol and added dropwise to the mixture at a rate of $0.5 \mathrm{~mL} / \mathrm{min}$ under vigorous stirring. After stirring at room temperature for $6 \mathrm{~h}$, the obtained products were centrifuged and washed twice with ethanol and once with distilled water. To further remove the surfactant template of CTAB, the product was stirred with saturated ammonium nitrate ethanol solution for $12 \mathrm{~h}$. The resulting product was centrifuged, and washed it with double-distilled water extensively.

\subsubsection{Preparation of $\mathrm{IrO}_{2} @ M S N @ P D A N P s$}

In this step, we dissolved $0.2 \mathrm{~g}$ dopamine in Tris buffer solution $(40 \mathrm{~mL}, 0.01 \mathrm{M}, \mathrm{pH}=8.5)$, and then mixed it with the as-prepared IrO ${ }_{2} @ M S N$ NPs. After stirring it at room temperature for $4 \mathrm{~h}$, the color of the solution changed into dark brown because of the oxidation, and the formed PDA coated IrO ${ }_{2} @ M S N$

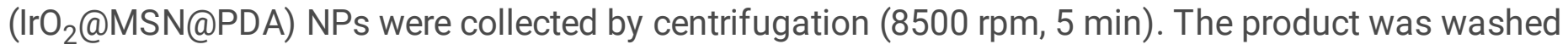
three times with ethanol and water to remove any possible remnants.

\subsubsection{Preparation of IrO ${ }_{2} @ M S N @ P D A-B S A N P s$}

IrO ${ }_{2} @ M S N @ P D A-B S A$ was synthesized by the amidation reaction between BSA and PDA. Specifically, the as-prepared IrO ${ }_{2} @ M S N @ P D A$ and $0.25 \mathrm{~g}$ BSA were added to $15 \mathrm{~mL}$ phosphate buffer $\left(\mathrm{Na}_{2} \mathrm{HPO}_{4^{-}}\right.$ $\mathrm{NaH}_{2} \mathrm{PO}_{4}, \mathrm{pH}=8.0$ ) under $4 \mathrm{~h}$ of ultrasounding at room temperature. Finally, the product was conventionally centrifuged (13000 rpm, $10 \mathrm{~min}$ ) and washed it three times with distilled water.

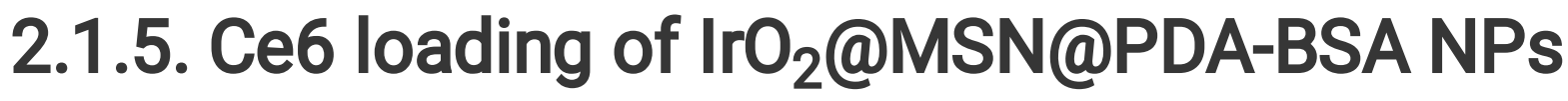

For the synthesis of IrO ${ }_{2} @ M S N @ P D A-B S A(C e 6)$, Ce6 was dissolved in DMSO at a concentration of 1000 $\mu \mathrm{g} / \mathrm{mL}$. Afterwards, the prepared Ce6 stock solution was diluted into different concentrations and mixed with IrO ${ }_{2} @ M S N @ P D A-B S A\left(I_{2}{ }_{2} @ M S N @ P D A-B S A\right.$ finally at $1000 \mu \mathrm{g} / \mathrm{mL}$, Ce6 finally at 50, 100, and 200 $\mu \mathrm{g} / \mathrm{mL}$ ). Then, the mixture was magnetically stirred overnight at room temperature. Thereafter, the reaction products were centrifuged at 12000 rpm for 8 min to obtain $\mathrm{IrO}_{2} @ M S N @ P D A-B S A(C e 6)$ NPs. 
The supernatant containing excess Ce6 was carefully collected for the loading amount calculation of Ce6. In brief, we used UV-vis-NIR spectroscopy to read the absorbance at $404 \mathrm{~nm}$ of the supernatant to reckon the concentration of $\mathrm{Ce} 6$ as per the absorbance-concentration standard curve. The loading efficiency of Ce6 was calculated by $\mathrm{W}_{\mathrm{t}} / \mathrm{W} \times 100 \%\left(\mathrm{~W}_{\mathrm{t}}\right.$ and $\mathrm{W}$ stand for the weight of loading Ce 6 and total Ce6, respectively.), and the loading percentage of Ce6 was calculated by $W_{t} / W_{S} \times 100 \%\left(W_{t}\right.$ and $W_{s}$ stand for the weight of loading $\mathrm{Ce} 6$ and the weight of $\mathrm{IrO}_{2} @ M S N @ P D A-B S A$, respectively.).

\subsection{Measurement of the dissolved oxygen content}

In this step, the catalase-like catalytic efficiency of IrO ${ }_{2} @ M S N @ P D A-B S A$ at different temperature $\left(37^{\circ} \mathrm{C}\right.$ and $80^{\circ} \mathrm{C}$ ) was evaluated by mixing $1 \mathrm{rO}_{2} @ M S N @ P D A-B S A$ (finally concentration at $200 \mu \mathrm{g} / \mathrm{mL}$ ) with various concentration of $\mathrm{H}_{2} \mathrm{O}_{2}$ (finally at $5,10,20$ and $50 \mu \mathrm{M}$ ). After the addition of $\mathrm{H}_{2} \mathrm{O}_{2}$, we used an oxygen probe (JPBJ-608 portable dissolved oxygen meter, Shanghai REX Instrument Factory) to monitor the dissolved oxygen content, and use a digital camera to record the bubble releasing of the reaction. At the same condition, the IrO ${ }_{2} @ M S N @ P D A$ without the addition of $\mathrm{H}_{2} \mathrm{O}_{2}$ was set as a control.

\subsection{Detection of the singlet oxygen}

1,3-diphenylisobenzofuran (DPBF), a classical probe for the measurement of singlet oxygen, was employed for the detection of the singlet oxygen. Briefly, 2.95 mL IrO ${ }_{2} @ M S N @ P D A-B S A(C e 6)$ in dimethyl sulfoxide was mixed with $50 \mu \mathrm{L}$ DPBF in dimethyl sulfoxide. The terminal concentration of IrO ${ }_{2} @ M S N @ P D A-B S A(C e 6)$ and DPBF was $20 \mu \mathrm{g} / \mathrm{mL}$ and $10 \mu \mathrm{M}$, respectively. Then, the mixture was added with $\mathrm{H}_{2} \mathrm{O}_{2}(10 \mathrm{mM}, 45 \mu \mathrm{L})$, while the mixture added with $\mathrm{H}_{2} \mathrm{O}(45 \mu \mathrm{L})$ was set as the control group. We exposed the above solutions to a $660 \mathrm{~nm}$ NIR laser $\left(0.3 \mathrm{~W} / \mathrm{cm}^{2}\right)$ in a dark environment for $20 \mathrm{~min}$, and used the Uv-vis-NIR spectrophotometer (Lambda 25, PerkinElmer, USA) to record the absorption intensity at designed time intervals.

\subsection{Photothermal Conversion Performance}

In order to explore the photothermal conversion performance, the as-prepared IrO 2 @MSN@PDA$\mathrm{BSA}(\mathrm{Ce} 6)$ was prepared in different concentrations $(0,100,250$ and $500 \mu \mathrm{g} / \mathrm{mL}$ in saline). Then, $100 \mu \mathrm{L}$ of the above samples were added in each well of a 96-well plate and exposed to the $808 \mathrm{~nm}$ NIR laser (1 $\left.\mathrm{W} / \mathrm{cm}^{2}, 5 \mathrm{~min}\right)$. To investigate the power density-dependent thermal characteristics, IrO ${ }_{2} @ M S N @ P D A-$ $\mathrm{BSA}(\mathrm{Ce} 6)$ with the concentration of $200 \mu \mathrm{g} / \mathrm{mL}$ was select to be irradiated with $808 \mathrm{~nm}$ NIR laser at different power $\left(0.5,0.8\right.$ and $\left.1 \mathrm{~W} / \mathrm{cm}^{2}\right)$ for $5 \mathrm{~min}$. The photothermal stability of $1 \mathrm{rO}{ }_{2} @ M S N @ P D A-$ $\mathrm{BSA}(\mathrm{Ce} 6)$ was also validated via the $808 \mathrm{~nm}$ NIR laser irradiation $\left(0.8 \mathrm{~W} / \mathrm{cm}^{2}\right)$ for $5 \mathrm{on} /$ off cycles (laser on for $10 \mathrm{~min}$ and laser off for $10 \mathrm{~min}$ in each cycle). We use FLIR ${ }^{\mathrm{TM}}$ E60 camera (FLIR, USA) to record the temperature increment $(\Delta T)$ of the above experiment for specific analysis.

\subsection{In vitro cellular viability}

In this section, L929 cells were chosen to assess the potential cellular cytotoxicity of $1 \mathrm{rO} \mathrm{O}_{2} @ M S N @ P D A-$ BSA in vitro. On the one hand, the CCK8 kit was performed to detect the cell viability after cultured with 
IrO ${ }_{2} @ M S N @ P D A-B S A(C e 6) . I n$ brief, L929 cells were seeded into 96-well plate (8000 cells/well) and maintained at $37^{\circ} \mathrm{C}$ in a humidified atmosphere with $5 \% \mathrm{CO}_{2}$. After $24 \mathrm{~h}$, the medium was replaced by various concentrations (100 $\mu \mathrm{L}, 0,50,100,250$ and $500 \mu \mathrm{g} / \mathrm{mL}$ in RMPI1640) of IrO $2 @ M S N$ @ PDA$\mathrm{BSA}(\mathrm{Ce} 6)$. Another $24 \mathrm{~h}$ later, $100 \mu \mathrm{L}$ fresh RMPI1640 with $10 \mu \mathrm{L}$ CCK8 test solution was added in each tested well to replace the old solution and then incubated for another $2 \mathrm{~h}$. Using a microplate reader to read the absorbency of each well at $450 \mathrm{~nm}$ to calculate cell viability. On the other hand, calcein-AM/PI Live/Dead kit was used to further determine the cytocompatibility of IrO ${ }_{2} @ M S N @ P D A-B S A(C e 6) . L 929$ cells were cultured and disposed of with the same as the CCK8 assay but lastly stained with calcein$\mathrm{AM} / \mathrm{PI}(100 \mu \mathrm{L})$ based on the manufacturer for $30 \mathrm{~min}$ at $37^{\circ} \mathrm{C}$. The counterstained cellular morphology was recorded using a fluorescence microscope (Olympus BX53).

\subsection{In vitro tumor therapy}

To study the cytotoxic effects of IrO $2 @$ MSN@PDA-BSA(Ce6) in vitro, HT29 cells were seeded into 96-well plates at a density of $8 \times 10^{3}$ cells/well and maintained in a humidified cell-incubator with $5 \% \mathrm{CO}_{2}$ at $37^{\circ} \mathrm{C}$ overnight for cell attachment. Then, each well was filled with $100 \mu \mathrm{L} \mathrm{IrO}_{2} @ \mathrm{MSN} @ P D A-B S A(C e 6)$ (in DMEM, $200 \mu \mathrm{g} / \mathrm{mL})$ and continue culturing for $12 \mathrm{~h}$. Then, we divided cells into 4 groups $(n=6)$. Cells in group 2 were irradiated with $808 \mathrm{~nm}$ laser $\left(1 \mathrm{~W} / \mathrm{cm}^{2}, 5 \mathrm{~min}\right)$ to assess the effect of PTT. Cells in group 3 were exposed to $660 \mathrm{~nm}$ laser $\left(0.3 \mathrm{~W} / \mathrm{cm}^{2}, 3 \mathrm{~min}\right)$ and cells in group 4 were treated with the medium containing $\mathrm{H}_{2} \mathrm{O}_{2}(100 \mu \mathrm{mol} / \mathrm{L})$ and the $\mathrm{pH}$ was adjusted to 6.0 with $\mathrm{HCl}$. Cells in group 5 were exposed to

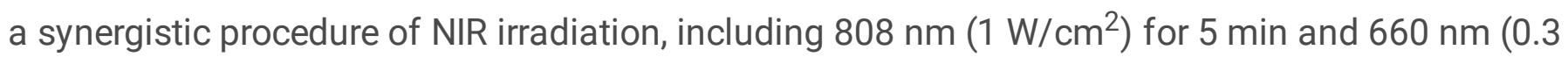
$\mathrm{W} / \mathrm{cm}^{2}$ ) for $3 \mathrm{~min}$. Cells treated with DMEM without other intervention were set as the control (group 1 ). Finally, we used CCK-8 and the calcein-AM/PI Live/Dead staining to evaluate the relative viabilities of cells.

\subsection{In vitro hemocompatibility}

The hemocompatibility of $\mathrm{Ir}_{2} @ M S N @ P D A-B S A(\mathrm{Ce} 6)$ was investigated by the typical in vitro hemolysis assay as below: fresh complete blood samples $(1 \mathrm{~mL})$ were collected from healthy $\mathrm{KM}$ mice and centrifuged (3000 rpm, $3 \mathrm{~min}, 4^{\circ} \mathrm{C}$ ) to obtain the mouse red blood cells (mRBCs). After that, the harvested mRBCs were washed with PBS three times and reposited in PBS for further experiments. Then, the above mRBCs dispersions $(0.3 \mathrm{~mL})$ was mixed with $1 \mathrm{~mL}$ of different concentrations $(100,250$ and $500 \mu \mathrm{g} / \mathrm{mL})$ of $1 \mathrm{rO}{ }_{2} @ M S N @ P D A-B S A$ and cultured at $37^{\circ} \mathrm{C}$. Meanwhile, mRBCs dispersions $(0.3 \mathrm{~mL})$ were incubated with $1 \mathrm{~mL}$ of PBS (negative control) or $1 \mathrm{~mL}$ of DI water (positive control). After incubating for $4 \mathrm{~h}$, the supernatant of the above mixture was gathered via centrifugation (12000 rpm, $5 \mathrm{~min}$ ). Subsequently, we recorded the absorbance of the supernatants at $580 \mathrm{~nm}$ to compute the hemolysis percentage (HP) according to literature.

\subsection{In vivo biocompatibility and biodistribution}

To evaluate the biocompatibility and biodistribution of IrO ${ }_{2} @ M S N @ P D A-B S A(C e 6)$ in vivo, the healthy KM female mice (SPF grade) were randomly sent into two groups ( $n=24$ per group). All animal experiments 
were conducted under the protocols approved by the Laboratory Animal Center of Changhai Hospital of Second Military Medical University, the policies of National Ministry of Hkiuealth. One group was intravenously (I.V.) injected with saline as a control, another group was injected with $\mathrm{IrO}_{2} @ M S N @ P D A-$ BSA(Ce6) solution ( $250 \mu \mathrm{L}, 1 \mathrm{mg} / \mathrm{mL}$ in PBS). The body weight of all experimental mice was weighed and recorded per two days. Mice were heart punctured for collect blood samples after anesthesia on 1, 7, 28 days and then were euthanized for organs collection. The blood samples were used for blood routine analysis and blood biochemical index testing in virtue of a Sysmex XS-800i automated hematology analyzer and a DxC 800 automatic biochemical analyzer. These crucial organs (heart, lung, liver, kidney, and spleen) were partly sectioned and immediately dipped in $4 \%$ polyformaldehyde for hematoxylin and eosin (H\&E) staining. Besides, the remaining part of the organs was used for quantitative detection of the Silicon (Si) ion biodistribution through the Agilent 700 Series ICP-OES.

\subsection{In vivo tumor therapy}

HT29 cells ( $10^{7}$ cells per mouse, in $150 \mu \mathrm{L}$ of serum-free DMEM) were subcutaneously implanted into the right back of the Balb/c nude mice (female, 4-6 weeks old). Three weeks after the cell-injection, a tumor nodule about $0.15-0.20 \mathrm{~cm}^{3}$ in each mouse was established. Then, the tumor mice were randomly allocated to five groups with six mice in each group as follows: mice in group 1 were I.V. injected with saline and served as the control group. Mice in group 2 were given with IrO ${ }_{2} @ M S N @ P D A-B S A(C e 6)$ solution ( $200 \mu \mathrm{L}, 1 \mathrm{mg} / \mathrm{mL}$ in PBS, I.V.) for PTT. Mice in group 3 were treated with IrO ${ }_{2} @ M S N @ P D A-$ BSA(Ce6) solution ( $200 \mu \mathrm{L}, 1 \mathrm{mg} / \mathrm{mL}$ in PBS, I.V.) for PDT. With regard to the dual-modal tumor therapy, $200 \mu \mathrm{L}$ (I.V.) and $20 \mu \mathrm{L}$ (I.T.) IrO ${ }_{2} @ M S N @ P D A-B S A(C e 6)$ were separately injected in group 4 and group 5. Twelve hours after the injection, mice in group 1 and group 2 were irradiated with $808 \mathrm{~nm}$ NIR laser $\left(1.0 \mathrm{~W} / \mathrm{cm}^{2}\right)$ for $5 \mathrm{~min}$, while mice in group 3 were subjected to the $660 \mathrm{~nm}$ laser $\left(0.3 \mathrm{~W} / \mathrm{cm}^{2}\right)$ for $5 \mathrm{~min}$. As the combined treatment group, the mice in group 4 and group 5 were successively exposed to $808 \mathrm{~nm} \mathrm{NIR}$ laser $\left(1.0 \mathrm{~W} / \mathrm{cm}^{2}\right)$ and $660 \mathrm{~nm}$ laser $\left(0.3 \mathrm{~W} / \mathrm{cm}^{2}\right)$ for $5 \mathrm{~min}$. The FLIR E60 infrared camera was exploited to keep the record of $\Delta T$ measurement and thermal imaging during the treatments. Mice in all groups were then raised for 4 weeks, and we measured the tumor volume every 3 days. The efficiency of in vivo tumor treatment was assessed by the relative tumor volume.

\subsection{Statistical analysis}

All the data acquest from the above experiments were reported as mean \pm standard deviation (SD) and statistically analyzed with one-way ANOVA. $P$ values $<0.05$ was regard as statistically significant. Data indicated with $(*)$ deputize for $p<0.05$, (**) for $p<0.01$, and $(* \star *)$ for $p<0.001$.

\section{Results And Discussions}

\subsection{Synthesis and Characterization of $\mathrm{IrO}_{2} @ M S N @ P D A-$ BSA}


Colloidal-stable polyvinylpyrrolidone (PVP)-decorated $\mathrm{IrO}_{2} \mathrm{NPs}\left(\mathrm{PVP}-\mathrm{IrO}_{2}\right)$ were prepared through facile hydrolysis and then coated with a thin layer of MSN to carry Ce6 through physical adsorption. PDA was then coated on the surfaces of the $1 \mathrm{rO}_{2} @ M S N$ particles under alkaline conditions because DA self-

polymerizes to form PDA. A BSA modifier was grafted onto the $1 \mathrm{r} \mathrm{O}_{2} @ M S N @ P D A$ surface under ultrasonic conditions through an amidation reaction between the - $\mathrm{COOH}$ group of $\mathrm{BSA}$ and the $-\mathrm{NH}_{2}$ group of PDA in a buffered solution of $\mathrm{Na}_{2} \mathrm{HPO}_{4}-\mathrm{NaH}_{2} \mathrm{PO}_{4}$ to achieve colloidal stability (Scheme 1). The morphology of the product was analyzed using SEM and TEM. A spherical shape with an average diameter of approximately $84 \pm 13 \mathrm{~nm}$ (Figs. 1a and b) was obtained. Therefore, we can conclude that NPs have a certain degree of aggregation, which is attributed to the interaction between the PDA and BSA that were grafted onto the NPs. The preparation of samples for SEM and TEM may have resulted in NP aggregation as well. The hydration kinetic diameter and Tyndall effect of the $1 \mathrm{rO}_{2} @ M S N @ P D A-B S A$ NPs in distilled water and PBS remained constant and clearly visible after $12 \mathrm{~h}$ of storage. This indicates that the

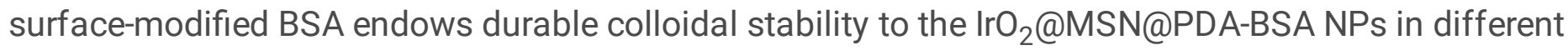
solutions. EDS (Fig. S1) and elemental mapping (Fig. 1d-f) confirmed the coexistence of O, Si, and Ir. Nitrogen adsorption-desorption isotherms were used to investigate the porous structure (Fig. 1g). The results indicated that the $1 \mathrm{IO}_{2} @ M S N @ P D A-B S A N P s$ had a high specific surface area $(149.6521 \mathrm{~m} / \mathrm{g})$ and large pore volume $\left(0.2 \mathrm{~cm}^{3} / \mathrm{g}\right)$. The average pore size was $5.7 \mathrm{~nm}$ (Fig. $\left.1 \mathrm{~h}\right)$. The XRD results of the

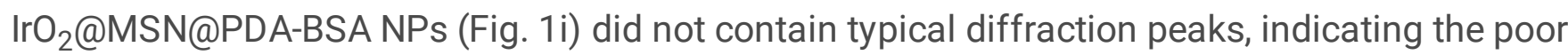
crystalline state of the NPs. The chemical structure of IrO ${ }_{2} @ M S N @ P D A-B S A ~ N P s$ was determined through FTIR. The absorption peak at $1089 \mathrm{~cm}^{-1}$ represents the tensile and asymmetric vibration of Si-O$\mathrm{Si}$ (Fig. S2), indicating the existence of $\mathrm{SiO}_{2}$ in the $\mathrm{IrO}_{2} @ M S N @ P D A-B S A N P s$. The vibration at $1422 \mathrm{~cm}^{-1}$ is attributed to the - $\mathrm{COOH}$ group of BSA. The vibration signals at $1640 \mathrm{~cm}^{-1}$ and $1500 \mathrm{~cm}^{-1}$ are attributed to the deformation vibrations of amide I $\left(-\mathrm{NH}_{2}\right)$ and amide II (-NH-) of BSA, respectively. The vibration peaks of the PDA and BSA amide groups due to the stretching of the $-\mathrm{NH}$ - group are located at $3400 \mathrm{~cm}^{-1}$ and $3000 \mathrm{~cm}^{-1}$, respectively. The peaks corresponding to the $-\mathrm{C}=\mathrm{C}$ - stretching vibration of PDA is located at $1500 \mathrm{~cm}^{-1}$. These results collectively confirm that PDA and BSA were successfully decorated onto the $1 \mathrm{rO} \mathrm{O}_{2} @ \mathrm{MSN}$ surface.

\subsection{Ce6 loading}

The conspicuous pore sizes of the IrO ${ }_{2} @ M S N @ P D A-B S A$ NPs are likely to facilitate guest molecule loading. A classical PSA named Ce6 was chosen as the model drug to be loaded onto the synthesized IrO ${ }_{2} @ M S N @ P D A-B S A$. It is essential to evaluate the loading performance of $\mathrm{Ir}_{2} @ M$ MSN@PDA-BSA because the tumor PDT is dose-dependent. The UV-vis-NIR spectra of $\mathrm{IrO}_{2} @ M S N @ P D A-B S A$ before and after the loading of Ce6 are shown in Fig. 2b. The NPs carrying Ce6 have two typical characteristic peaks at $404 \mathrm{~nm}$ and $665 \mathrm{~nm}$, in comparison to the spectrum of the pure $1 \mathrm{IO}_{2} @ \mathrm{MSN} @ P D A-B S A$. This proves that Ce6 was successfully loaded onto IrO ${ }_{2} @ M S N @ P D A-B S A$. The Ce6 loading of IrO $_{2} @ M S N @ P D A-B S A$ was then optimized by varying the concentration of Ce6. Ce6 concentrations of 50, 100, and $200 \mu \mathrm{g} / \mathrm{mL}$ 
resulted in Ce6 loading values of approximately 76.3 \%, 61.3 \%, and 43.0\% on IrO ${ }_{2} @ M S N @ P D A-B S A$, respectively. The $\mathrm{Ce} 6$ loading ratio was calculated by dividing the weight of the loaded $\mathrm{Ce} 6$ with the weight of $\mathrm{IrO}_{2} @ \mathrm{MSN} @$ PDA-BSA, which was equal to 3.8 \%, 6.1 \%, and 8.6 \% at Ce6 concentrations of 50, 100 , and $200 \mu \mathrm{g} / \mathrm{mL}$, respectively (Fig. 2c). According to the abovementioned results, a Ce6 concentration of $200 \mu \mathrm{g} / \mathrm{mL}$ was selected for the subsequent experiments.

\subsection{Catalytic efficiency and ${ }^{1} \mathrm{O}_{2}$ generating capacity}

IrO ${ }_{2} @ M S N @ P D A-B S A$ can improve the PDT efficiency by catalyzing the decomposition of $\mathrm{H}_{2} \mathrm{O}_{2}$ to generate endogenous $\mathrm{O}_{2}$ due to the catalase-like activity of $\mathrm{IrO}_{2}$. The addition of $\mathrm{H}_{2} \mathrm{O}_{2}$ to the IrO ${ }_{2} @ M S N @ P D A-B S A$ solution results in the immediate generation of several $\mathrm{O}_{2}$ bubbles, as shown in Fig. 2d. This intuitively confirms the catalytic ability of $\mathrm{IrO}_{2}$. Further, the catalytic efficiency of IrO ${ }_{2} @ M S N @ P D A-B S A$ was concentration-dependent. An increase in the $1 \mathrm{rO}_{2} @ M S N @ P D A-B S A$ concentration led to an increase in the concentration of the dissolved $\mathrm{O}_{2}$ (Fig. 2e). The $\mathrm{IrO}_{2} @ M S N @ P D A-$ BSA NPs possess the required thermal stability and are superior to the traditional catalase, which is vulnerable to hyperthermia (Fig. 2g). The catalytic ability of IrO ${ }_{2} @ M S N @ P D A-B S A$ was satisfactory at 37 ${ }^{\circ} \mathrm{C}$ and highly dependent on the substrate concentration (Fig. 2f). The catalytic ability of IrO ${ }_{2} @ M S N @ P D A-B S A$ remained constant even after increasing the temperature to $80^{\circ} \mathrm{C}$. This thermal stability further enhances PDT efficiency in the PTT-induced high-temperature environment.

The amount of ${ }^{1} \mathrm{O}_{2}$ contained in the solution was measured through light radiation to verify whether the $\mathrm{O}_{2}$ generated by IrO ${ }_{2} @ M S N @ P D A-B S A$ could be utilized to enhance the tumor PDT. The irradiation of the IrO ${ }_{2} @ M S N @ P D A-B S A$ solution led to a reduction in the light absorption by the DPBF, thereby confirming the generation of ${ }^{1} \mathrm{O}_{2}\left({ }^{1} \mathrm{O}_{2}\right.$ can oxidize the probe of DPBF and catalyze its discoloring reaction). In addition, it was observed that the rate of reduction in the light absorption increased with the addition of $\mathrm{H}_{2} \mathrm{O}_{2}$. This confirms the ability of the IrO ${ }_{2} @ M S N @ P D A-B S A ~ N P s$ to enhance ${ }^{1} \mathrm{O}_{2}$ generation in the presence of $\mathrm{H}_{2} \mathrm{O}_{2}$. The improved ${ }^{1} \mathrm{O}_{2}$ generation indicates that $\mathrm{IrO}_{2} @ M S N @ P D A-B S A$ can be used as an intelligent nanozyme system to facilitate tumor PDT in the TME.

\subsection{Photothermal Conversion Performance}

In addition to enhancing the tumor PDT, IrO ${ }_{2} @ M S N @ P D A-B S A$ is a PTA that can be used in the PTT of tumors. The absorbance capacity of $\mathrm{IrO}_{2} @ M S N @ P D A-B S A$ for wavelengths ranging from 400 to 1000 nm was first studied. IrO ${ }_{2} @ M S N @ P D A-B S A$ demonstrated a high light absorbance capacity, and the light absorbance increased with increasing NP concentration in the abovementioned wavelength range (Fig. 2i). The absorbed light was partially transformed into heat. The photothermal ability of $\mathrm{IrO}_{2} @ M S N @ P D A-B S A$ was studied by varying the NIR laser power and NP concentration. The $\Delta T$ of IrO ${ }_{2} @ M S N @ P D A-B S A$ increased with the increasing concentration of the solution at a fixed power density, as shown in Fig. 3a. However, the $\Delta T$ of water was negligible. The $\Delta T$ values of the solutions at 
concentrations of 100,250 , and $500 \mathrm{mg} / \mathrm{mL}$ were $7.0,16.4$, and $30.2^{\circ} \mathrm{C}$, respectively. $1 \mathrm{rO}{ }_{2} @ M S N @ P D A-$ BSA was then used at a concentration of $250 \mathrm{mg} / \mathrm{mL}$ to study the impact of power density on heat production. The $\triangle \mathrm{T}$ values of $\mathrm{IrO}_{2} @ M S N @ P D A-B S A$ were $7.7,12.6$, and $16.4^{\circ} \mathrm{C}$ at power densities of 0.5 , 0.8 , and $1.0 \mathrm{~W} / \mathrm{cm}^{2}$ (808 $\mathrm{nm}$ ), respectively. An E60 thermal imaging camera (FLIR Systems, Inc., USA) was used to record the concentration, irradiation, and laser-power-density-dependent temperature surges of IrO ${ }_{2} @ M S N @ P D A-B S A$ (Figs. 3b and d). It was confirmed that the photothermal ability of IrO ${ }_{2} @ M S N @ P D A-B S A$ was dependent on the material concentration and laser power density. The photothermal conversion efficiency and heat transfer time constant (ts) were equal to $29.8 \%$ and 175.7 $\mathrm{s}$, both of which are comparable to the values obtained for graphene and black phosphorus nanosheets (Figs.3f and g) [34, 35]. IrO ${ }_{2} @ M S N @ P D A-B S A$ is considered photothermally stable because its $\triangle T$ variation during the five rounds of NIR laser irradiation substantial (Fig. 3e).

\subsection{In Vitro Biocompatibility Assay}

In vitro biocompatibility, including cytocompatibility and hemocompatibility, is an essential factor in the biomedical applications of nanomaterials. Therefore, the cytocompatibility of $\mathrm{IrO}_{2} @ M S N @ P D A-B S A(C e 6)$ was assessed using a CCK-8 cell viability assay and calcein-AM/PI double staining. The cell viabilities were maintained above $95 \%$ after $24 \mathrm{~h}$ of co-cultivation with varying concentrations of $1 \mathrm{rO}_{2} @ \mathrm{MSN} @ P D A-$ BSA(Ce6), as shown in the CCK-8 results depicted in Fig. 4a. There were no evident differences between the abovementioned sample and the control group. These trends are similar to the results of CCK-8 and calcein-AM/PI double staining, which stained the live cells and dead cells green and red, respectively (Fig. 4b-f). This indicates that there were no obvious differences between the results of the experimental and control groups after culturing the samples for $24 \mathrm{~h}$. These results indicate that the cytocompatibility of $\mathrm{IrO}_{2} @ M S N @ P D A-B S A(\mathrm{Ce} 6)$ is satisfactory within experimental dosages. The hemocompatibility of IrO ${ }_{2} @ M S N @ P D A-B S A(C e 6)$ was evaluated using a hemolysis assay. The HP of $\mathrm{IrO}_{2} @ M S N @ P D A-$ $\mathrm{BSA}(\mathrm{Ce} 6)$ remained lower than $5 \%$, even at a high material concentration of $500 \mu \mathrm{g} / \mathrm{mL}$. The HP values were equal to $0.4 \pm 0.14 \%, 1.2 \pm 0.25 \%$, and $2.16 \pm 0.3 \%$ at IrO ${ }_{2} @ M S N @ P D A-B S A(C e 6)$ concentrations of 100,250 , and $500 \mu \mathrm{g} / \mathrm{mL}$, respectively (Fig. $4 \mathrm{~g}$ ). In addition, the mRBCs of the control and experimental groups were completely separated from the solution with relative ease, whereas the mRBCs in the positive control were completely ruptured (Fig. 4h). The hemolysis assay indicated that the NPs had a minimal impact on the structural integrity of mRBCs, thereby ensuring the safety of intravenous material injections.

\subsection{In Vivo Biocompatibility and Biodistribution}

The biocompatibility of $1 \mathrm{IO}_{2} @ M S N @ P D A-B S A(\mathrm{Ce} 6)$ in animals was also studied. The body weights of mice were measured every two days after the I.V. materials injection. The body weights of the experimental and control groups did not differ significantly $(p>0.05)$, as shown in Fig. $5 a$. However, the blood routine (Fig. S3) and serum biochemistry parameters (Fig. 5b) of the mice administered with IrO ${ }_{2} @ M S N @ P D A-B S A(C e 6)$ were not similar to those of the control group $(p>0.05)$. The potential toxicity 
of $\mathrm{IrO}_{2} @ \mathrm{MSN} @ P D A-B S A(\mathrm{Ce} 6)$ to vital organs, such as the heart, liver, spleen, lungs, and kidneys, was also evaluated. The H\&E staining of these organs demonstrated that no obvious damage was caused during the preset feeding periods (1, 7, and 28 days).This indicates that $1 \mathrm{rO} \mathrm{O}_{2} @ M S N @ P D A-B S A(C e 6)$ does not cause acute or chronic organ damage. The potential metabolic pathway of IrO $\mathrm{r}_{2} @ \mathrm{MSN} @ P D A-B S A(\mathrm{Ce} 6)$ was then investigated by conducting an in vivo biodistribution of $\mathrm{Si}$ ions. The accumulation of $\mathrm{Si}$ in the liver and kidney one day after the injection was higher than that observed in the other organs due to the non-specific uptake of the reticuloendothelial system. The amount of $\mathrm{Si}$ in the major organs gradually decreased with time. As a result, the concentration of $\mathrm{Si}$ in the tested organs was lower than $5 \mu \mathrm{g} / \mathrm{g} 28$ days after the injection.

\subsection{In Vitro PTT/PDT Tumor Therapy.}

The efficiency of the combined tumor therapy in HT-29 cells and tumor-bearing nude mice was studied to realize the desirable biocompatibility of $\mathrm{IrO}_{2} @ M S N @ P D A-B S A(\mathrm{Ce} 6)$ in vitro and in vivo. The HT-29 cells cultured with IrO ${ }_{2} @ M S N @ P D A-B S A(C e 6)$ in the absence of light intervention did not report excessive cell death. However, the survival rate of the cells after being subjected to $808 \mathrm{~nm}$ NIR laser irradiation was reduced to $48.9 \%$ ( ${ }^{\star \star \star} p<0.001$, versus control, Fig. $6 \mathrm{a}$ ) due to the excellent photothermal conversion ability of IrO ${ }_{2} @ M S N @ P D A(C e 6)$. In comparison with the control group, the viability of the HT-29 cells irradiated with a $660 \mathrm{~nm}$ laser decreased to $65.8 \%$ (PDT group, $* \star \star \mathrm{p}<0.001$, versus control). The addition of $\mathrm{H}_{2} \mathrm{O}_{2}$ to the DMEM under conditions similar to those of the PDT group drastically reduced the viability of the HT-29 cells to $17.6 \%$ ( $* \star * p<0.001$, versus control; $* \star * p<0.001$, versus PDT). The differences in the cell viability values indicate that the co-existence of $\mathrm{H}_{2} \mathrm{O}_{2}$ and $\mathrm{IrO}_{2} @ M S N @ P D A-B S A(C e 6)$ could enhance the tumor PDT effect. This is because $\mathrm{IrO}_{2}$ catalyzed the decomposition of $\mathrm{H}_{2} \mathrm{O}_{2}$ to produce endogenous oxygen, which was further sensitized by the Ce6 while being irradiated by a $660 \mathrm{~nm}$ laser. Owing to the PTT and CAT-mimicking abilities of $\mathrm{IrO}_{2} @ M S N @ P D A-B S A(\mathrm{Ce} 6)$, the HT-29 cells were almost completely

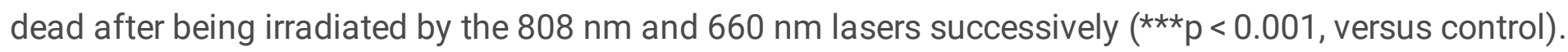
The results of the calcein-AM/PI live/dead staining were similar to those of the CCK-8 cell viability assay. The HT-29 cells in the control group were stained with a strong green fluorescence, whereas most HT-29 cells treated with PTT, PDT, enhanced PDT, and PDT/PTT were stained red (Fig. $6 \mathrm{~b}-f$ ). This validates the in vitro therapeutic effect of $\mathrm{IrO}_{2} @ M S N @ P D A-B S A(C e 6)$.

\subsection{In Vivo Combined Tumor Therapy}

The in vitro therapeutic effect investigation provides preliminary confirmation that $1 \mathrm{r} \mathrm{O}_{2} @ M S N @ P D A-$ $\mathrm{BSA}(\mathrm{Ce} 6)$ is suitable for multimodal tumor therapy. This was verified by the tests conducted on animals. The variations in the temperatures of the tumor-bearing nude mice that received the material injections were measured using a thermal imaging camera. The $\Delta T$ of the control group was only $4.3^{\circ} \mathrm{C}$ after being subjected to NIR irradiation at $808 \mathrm{~mm}(5 \mathrm{~min})$, whereas $\Delta T$ for the mice injected with the I.V. and I.T. materials were $10.3^{\circ} \mathrm{C}$ and $20.8^{\circ} \mathrm{C}$, respectively. The variation in the temperatures of the mice injected with the I.V. material also proved that IrO ${ }_{2} @ M S N @ P D A-B S A(C e 6)$ could passively accumulate at the tumor site 
through the EPR effect. The volume of the tumors of the mice belonging to the control group increased to 9.12 times their original values after 28 days of feeding. However, the tumor volumes of the PTT group increased to 2.56 times their original values ( ${ }^{\star \star *} p<0.001$, versus control). This indicates that PTT can kill a few cancer cells while the surviving ones continue to grow. Similarly, the tumor volumes of the PDT group increased to approximately 3.42 times their original values ( ${ }^{\star \star \star} p<0.001$, versus control). There was no obvious difference between the tumor volumes of the PDT and PTT groups $(p>0.05)$. This suggests that a single dose of PTT or PDT produces a certain therapeutic effect. However, the tumors of the mice in the combined therapy group were completely eradicated, irrespective of the material injection method (Figs. 7c and d). This confirms the superior efficiency of the combined tumor therapy of the $\mathrm{IrO}_{2} @ M S N @ P D A-B S A(\mathrm{Ce} 6)$ NPs.

\section{Conclusion}

An IrO ${ }_{2} @ M S N @ P D A-B S A(\mathrm{Ce} 6)$ nanoenzymatic composite platform for the treatment of tumors through the combined effects of PTT and PDT was designed in this study. The MSN coating introduced abundant pores for Ce6 loading, and the conjugated BSA endowed the NPs with sufficient biocompatibility in vitro and in vivo. The loading of $\mathrm{Ce} 6$ facilitated the photo-triggered generation of single oxygen, resulting in photodynamic cell death. $\mathrm{IrO}_{2}$ functions as a CAT-mimic to catalyze the decomposition of $\mathrm{H}_{2} \mathrm{O}_{2}$ in the TME to generate endogenous oxygen and alleviate the hypoxia of solid tumors. This enhances the PDT of $\mathrm{Ce} 6$ by offering local oxygen and promoting the generation of ${ }^{1} \mathrm{O}_{2}$. In addition, the PDA coating and $\mathrm{IrO}_{2} \mathrm{NPs}$ exhibited remarkably high photothermal conversion efficiencies, resulting in the ablation of solid tumors through hyperthermia. The therapeutic effect of $1 \mathrm{rO}_{2} @ \mathrm{MSN} @ P D A-B S A(\mathrm{Ce} 6)$ for multimodal tumor therapy was proved both in vitro and in vivo. The results indicated that the tumors of the mice in the combined therapy group could be completely eradicated. The findings of the present study highlight the feasibility of using theranostic nanoenzymes for translational medicine.

\section{Declarations}

\section{Ethics approval and consent to participate}

Not applicable

\section{Consent for publication}

Not applicable

\section{Availability of data and materials}

All data generated or analyzed during this study are included in this manuscript and its supplementary material

\section{Competing interests}


All authors declare that they have no conflict of interest or financial conflicts to disclose.

\section{Funding}

Not applicable

Authors' contributions

$\mathrm{HW}$ and QJ designed and performed the experiment, and wrote the manuscript. $\mathrm{KL}, \mathrm{CZ}, \mathrm{MX}$ and $\mathrm{SW}$ analyzed the data. ZF and JZ supervised the research

\section{Acknowledgements}

H. W. and Q. J. contributed equally to this work. This research is financially supported by Shanghai Sailing Program 20YF1448400, Naval Medical University Sailing Program 2019-QH-16, Shanghai Changhai Hospital Youth Found.

\section{Supporting Information}

Supporting Information is available from the online or from the author.

\section{References}

1. Siegel RL, Miller KD, Fuchs HE, Jemal A: Cancer Statistics, 2021. CA Cancer J Clin 2021, 71:7-33.

2. Zeng H, Chen W, Zheng R, Zhang S, Ji JS, Zou X, Xia C, Sun K, Yang Z, Li H, et al: Changing cancer survival in China during 2003-15: a pooled analysis of 17 population-based cancer registries. Lancet Glob Health 2018, 6:e555-e567.

3. Vasan N, Baselga J, Hyman DM: A view on drug resistance in cancer. Nature 2019, 575:299-309.

4. Herrmann J: Adverse cardiac effects of cancer therapies: cardiotoxicity and arrhythmia. Nat Rev Cardiol 2020, 17:474-502.

5. Liu Y, Bhattarai P, Dai Z, Chen X: Photothermal therapy and photoacoustic imaging via nanotheranostics in fighting cancer. Chem Soc Rev 2019, 48:2053-2108.

6. Liu S, Pan X, Liu H: Two-Dimensional Nanomaterials for Photothermal Therapy. Angew Chem Int Ed Eng/2020, 59:5890-5900.

7. Monro S, Colon KL, Yin H, Roque J, 3rd, Konda P, Gujar S, Thummel RP, Lilge L, Cameron CG, McFarland SA: Transition Metal Complexes and Photodynamic Therapy from a Tumor-Centered Approach: Challenges, Opportunities, and Highlights from the Development of TLD1433. Chem Rev 2019, 119:797-828.

8. Yang J, Hou M, Sun W, Wu Q, Xu J, Xiong L, Chai Y, Liu Y, Yu M, Wang H, et al: Sequential PDT and PTT Using Dual-Modal Single-Walled Carbon Nanohorns Synergistically Promote Systemic Immune Responses against Tumor Metastasis and Relapse. Adv Sci (Weinh) 2020, 7:2001088. 
9. Liang R, Liu L, He H, Chen Z, Han Z, Luo Z, Wu Z, Zheng M, Ma Y, Cai L: Oxygen-boosted immunogenic photodynamic therapy with gold nanocages@manganese dioxide to inhibit tumor growth and metastases. Biomaterials 2018, 177:149-160.

10. Liu P, Xie X, Shi X, Peng Y, Ding J, Zhou W: Oxygen-Self-Supplying and HIF-1alpha-Inhibiting CoreShell Nanosystem for Hypoxia-Resistant Photodynamic Therapy. ACS Appl Mater Interfaces 2019, 11:48261-48270.

11. Luo K, Wu H, Chen Y, Li J, Zhou L, Yang F, Huang M, An X, Wang S: Preparation of Bi-based hydrogel for multi-modal tumor therapy. Colloids Surf B Biointerfaces 2021, 200:111591.

12. Pucelik B, Sulek A, Barzowska A, Dabrowski JM: Recent advances in strategies for overcoming hypoxia in photodynamic therapy of cancer. Cancer Lett 2020, 492:116-135.

13. Cheng Y, Cheng H, Jiang C, Qiu X, Wang K, Huan W, Yuan A, Wu J, Hu Y: Perfluorocarbon nanoparticles enhance reactive oxygen levels and tumour growth inhibition in photodynamic therapy. Nat Commun 2015, 6:8785.

14. Chang M, Hou Z, Wang M, Wang M, Dang P, Liu J, Shu M, Ding B, Al Kheraif AA, Li C, Lin J: Cu2 MoS4 /Au Heterostructures with Enhanced Catalase-Like Activity and Photoconversion Efficiency for Primary/Metastatic Tumors Eradication by Phototherapy-Induced Immunotherapy. Small 2020, 16:e1907146.

15. Cheng X, He L, Xu J, Fang Q, Yang L, Xue Y, Wang X, Tang R: Oxygen-producing catalase-based prodrug nanoparticles overcoming resistance in hypoxia-mediated chemo-photodynamic therapy. Acta Biomater 2020, 112:234-249.

16. Sahu A, Min K, Jeon J, Yang HS, Tae G: Catalytic nanographene oxide with hemin for enhanced photodynamic therapy. J Control Release 2020, 326:442-454.

17. Wang D, Wu H, Lim WQ, Phua SZF, Xu P, Chen Q, Guo Z, Zhao Y: A Mesoporous Nanoenzyme Derived from Metal-Organic Frameworks with Endogenous Oxygen Generation to Alleviate Tumor Hypoxia for Significantly Enhanced Photodynamic Therapy. Adv Mater 2019, 31:e1901893.

18. Du B, Tung CH: Enzyme-Assisted Photodynamic Therapy Based on Nanomaterials. ACS Biomater Sci Eng 2020, 6:2506-2517.

19. Dan Q, Hu D, Ge Y, Zhang S, Li S, Gao D, Luo W, Ma T, Liu X, Zheng H, et al: Ultrasmall theranostic nanozymes to modulate tumor hypoxia for augmenting photodynamic therapy and radiotherapy. Biomater Sci 2020, 8:973-987.

20. Hou X, Tao Y, Pang Y, Li X, Jiang G, Liu Y: Nanoparticle-based photothermal and photodynamic immunotherapy for tumor treatment. Int J Cancer 2018, 143:3050-3060.

21. Nam J, Son S, Ochyl LJ, Kuai R, Schwendeman A, Moon JJ: Chemo-photothermal therapy combination elicits anti-tumor immunity against advanced metastatic cancer. Nat Commun 2018, 9:1074.

22. Hu K, Xie L, Zhang Y, Hanyu M, Yang Z, Nagatsu K, Suzuki H, Ouyang J, Ji X, Wei J, et al: Marriage of black phosphorus and $\mathrm{Cu}(2+)$ as effective photothermal agents for PET-guided combination cancer therapy. Nat Commun 2020, 11:2778. 
23. Murugan C, Sharma V, Murugan RK, Malaimegu G, Sundaramurthy A: Two-dimensional cancer theranostic nanomaterials: Synthesis, surface functionalization and applications in photothermal therapy. J Control Release 2019, 299:1-20.

24. Zhang Y, Lv F, Cheng Y, Yuan Z, Yang F, Liu C, Cao Y, Zhang K, Lu H, Zada S, et al: Pd@Au Bimetallic Nanoplates Decorated Mesoporous MnO2 for Synergistic Nucleus-Targeted NIR-II Photothermal and Hypoxia-Relieved Photodynamic Therapy. Adv Healthc Mater 2020, 9:e1901528.

25. Chen G, Ma B, Wang Y, Xie R, Li C, Dou K, Gong S: CuS-Based Theranostic Micelles for NIR-Controlled Combination Chemotherapy and Photothermal Therapy and Photoacoustic Imaging. ACS App/ Mater Interfaces 2017, 9:41700-41711.

26. Rong L, Zhang Y, Li WS, Su Z, Fadhil JI, Zhang C: Iron chelated melanin-like nanoparticles for tumorassociated macrophage repolarization and cancer therapy. Biomaterials 2019, 225:119515.

27. Sun W, Du Y, Liang X, Yu C, Fang J, Lu W, Guo X, Tian J, Jin Y, Zheng J: Synergistic triple-combination therapy with hyaluronic acid-shelled PPy/CPT nanoparticles results in tumor regression and prevents tumor recurrence and metastasis in 4T1 breast cancer. Biomaterials 2019, 217:119264.

28. Zhou L, Zhao J, Chen Y, Zheng Y, Li J, Zhao J, Zhang J, Liu Y, Liu X, Wang S: MoS2-ALG-Fe/G0x hydrogel with Fenton catalytic activity for combined cancer photothermal, starvation, and chemodynamic therapy. Colloids Surf B Biointerfaces 2020, 195:111243.

29. Wan G, Chen B, Li L, Wang D, Shi S, Zhang T, Wang Y, Zhang L, Wang Y: Nanoscaled red blood cells facilitate breast cancer treatment by combining photothermal/photodynamic therapy and chemotherapy. Biomaterials 2018, 155:25-40.

30. Ferroni C, Del Rio A, Martini C, Manoni E, Varchi G: Light-Induced Therapies for Prostate Cancer Treatment. Front Chem 2019, 7:719.

31. Sun W, Zhao X, Fan J, Du J, Peng X: Boron Dipyrromethene Nano-Photosensitizers for Anticancer Phototherapies. Small 2019, 15:e1804927.

32. Gu W, Zhang T, Gao J, Wang Y, Li D, Zhao Z, Jiang B, Dong Z, Liu H: Albumin-bioinspired iridium oxide nanoplatform with high photothermal conversion efficiency for synergistic chemophotothermal of osteosarcoma. Drug Deliv 2019, 26:918-927.

33. Zhen W, Liu Y, Lin L, Bai J, Jia X, Tian H, Jiang X: BSA-IrO2 : Catalase-like Nanoparticles with High Photothermal Conversion Efficiency and a High X-ray Absorption Coefficient for Anti-inflammation and Antitumor Theranostics. Angew Chem Int Ed Engl 2018, 57:10309-10313.

34. Gulzar A, Xu J, Yang D, Xu L, He F, Gai S, Yang P: Nano-graphene oxide-UCNP-Ce6 covalently constructed nanocomposites for NIR-mediated bioimaging and PTT/PDT combinatorial therapy. Dalton Trans 2018, 47:3931-3939.

35. Wan S, Zhang B, Li S, He B, Pu Y: Combination of PEG-decorated black phosphorus nanosheets and immunoadjuvant for photoimmunotherapy of melanoma. J Mater Chem B 2020, 8:2805-2813.

\section{Figures}


(a)

(d)

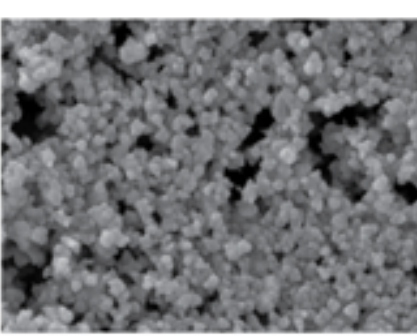

(g)
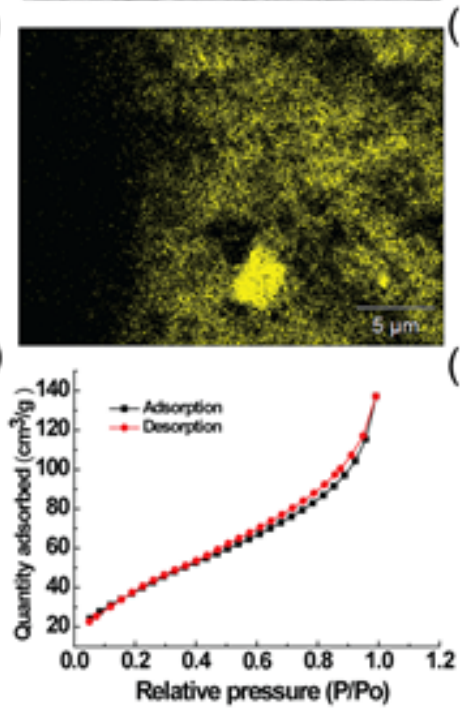

(b)

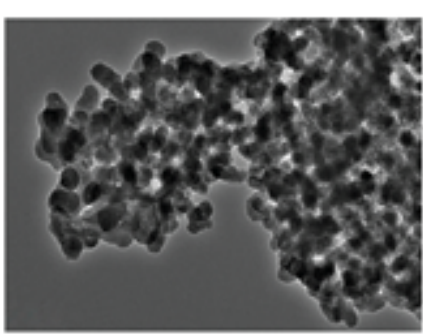

$(e)$

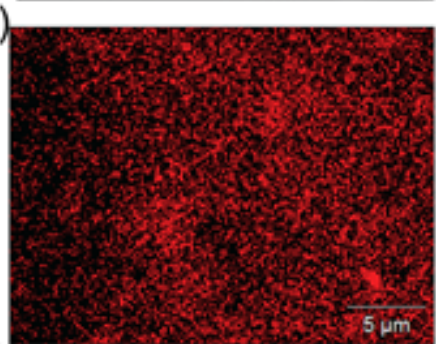

(h)

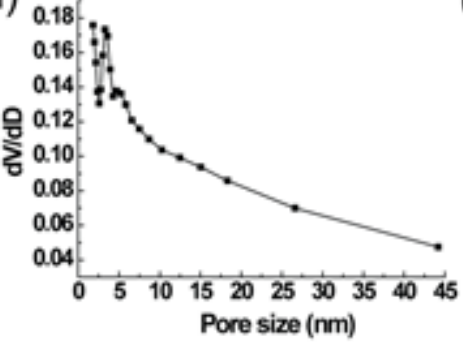

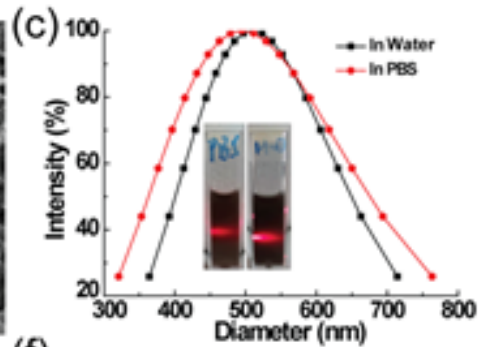

(f)

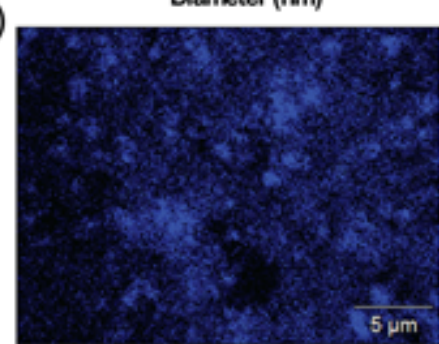

(i)

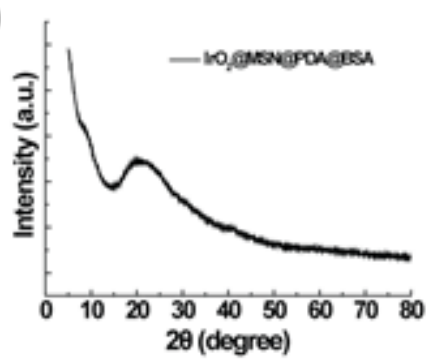

Figure 1

Characterization of IrO2@MSN@PDA-BSA NPs. (a) SEM, (b) TEM, (c) dynamic light scattering and solution photos (left: in PBS, right: in water); (d-f) elemental distribution mappings (d, O; e, Si; f, Ir); (g) nitrogen adsorption-desorption isotherm; (h) pore size of IrO2@MSN@PDA-BSA; (i) XRD pattern.

(a) 1.4

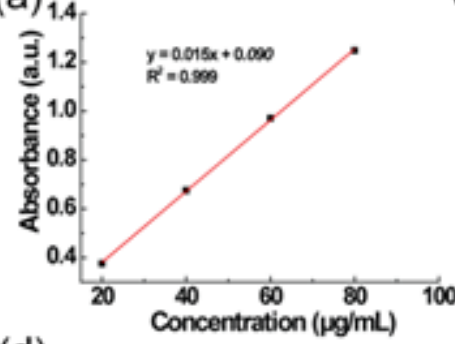

(d)

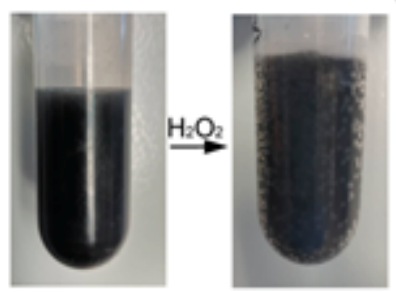

(g)

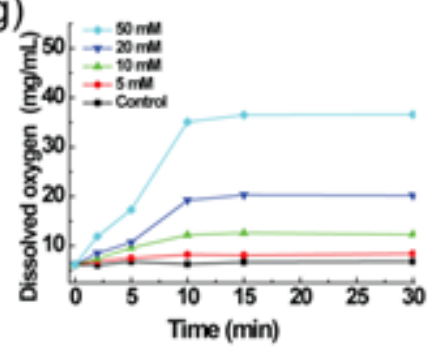

(b)

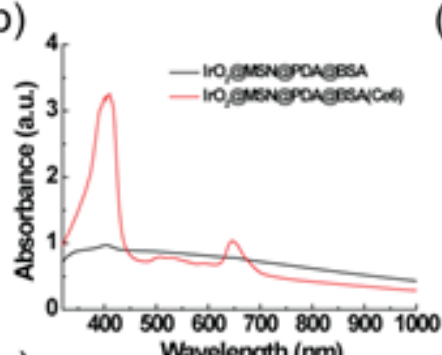

(e)

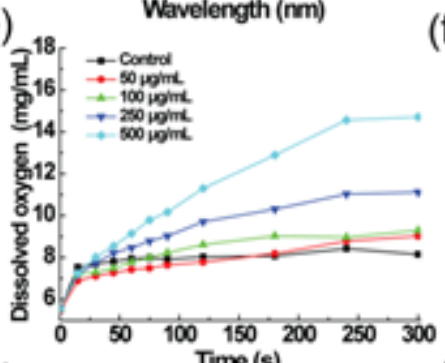

(h) 3.5

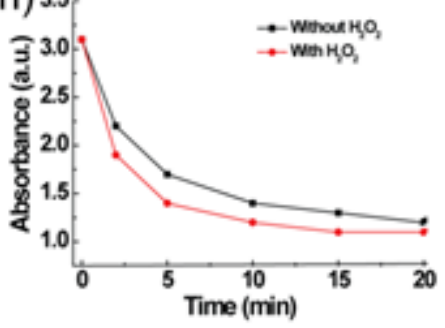

(c)

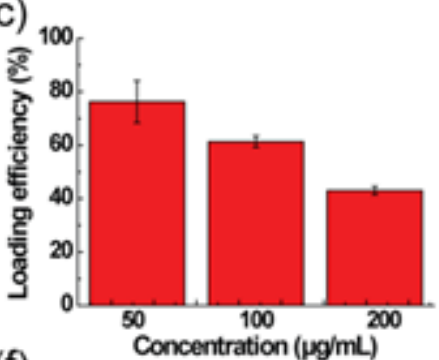

(f)

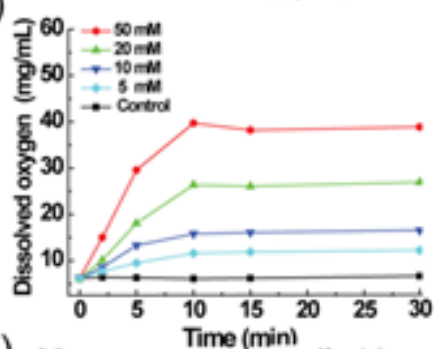

(i)

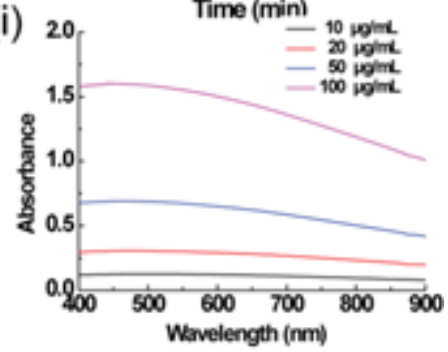


(a) Standard curve of Ce6; (b) light absorption of Ir02@MSN@PDA-BSA and IrO2@MSN@PDA-BSA(Ce6); (c) Ce6 loading efficiency of IrO2@MSN@PDA-BSA $(1000 \mu \mathrm{g} / \mathrm{mL})$ under different Ce6 concentrations; (d) photographs of IrO2@MSN@PDA-BSA solutions before and after the addition of H2O2; (e) 02 generation ability of IrO2@MSN@PDA-BSA with different concentrations; (f-g) 02 generation ability of IrO2@MSN@PDA-BSA solutions at (f) 37区 C and (g) 80冈 C with various concentrations of H2O2; $(\mathrm{h})$ the light absorption of IrO2@MSN@PDA-BSA(Ce6) with or without the addition of H2O2; (i) UV-vis spectra of IrO2@MSN@PDA-BSA NPs solutions.

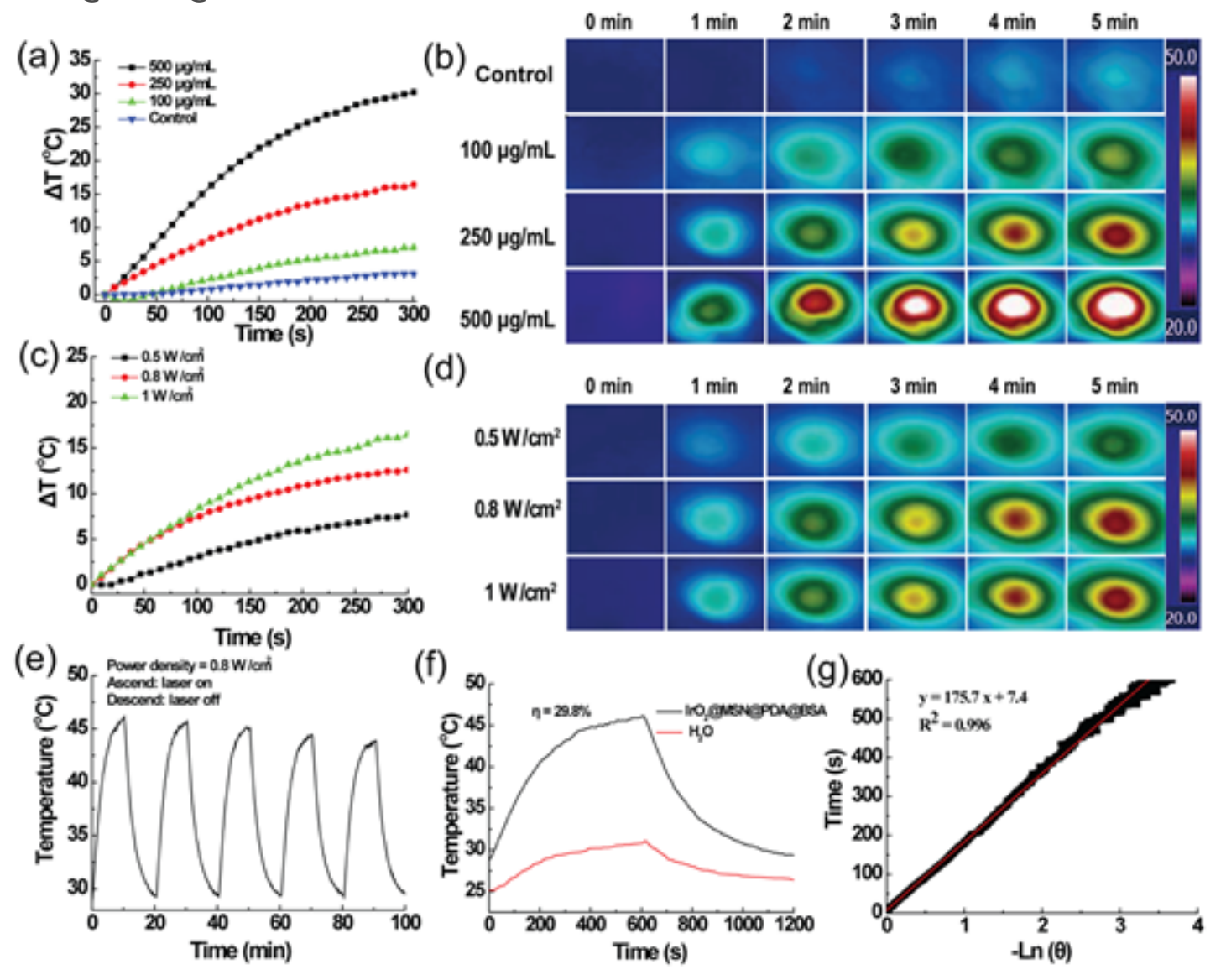

Figure 3

(a) Photothermal curves of IrO2@MSN@PDA-BSA NPs solution with different concentration upon 808 nm laser irradiation ( $5 \mathrm{~min}, 0.8 \mathrm{~W} / \mathrm{cm} 2)$; (b) the thermal images relevant to panel (a); (c) photothermal curves of IrO2@MSN@PDA-BSA NPs solution(250 mg/mL) under different laser power density irradiation(808nm,5min); (d) the thermal images relevant to panel (c); (e) temperature curve of IrO2@MSN@PDA-BSA solution during 5 irradiation and cooling cycles; (f) steady-state heating curves of IrO2@MSN@PDA-BSA NPs and water; (g) time constant for heat transfer of IrO2@MSN@PDA-BSA NPs. 
(a) 120

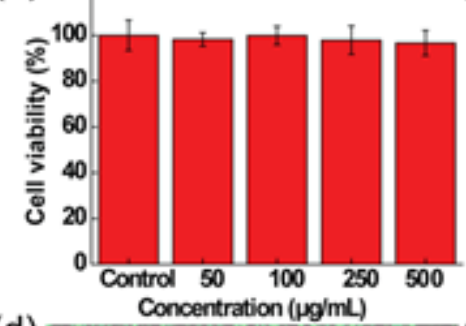

(d)

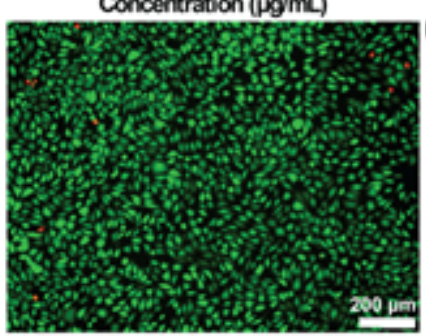

(g)

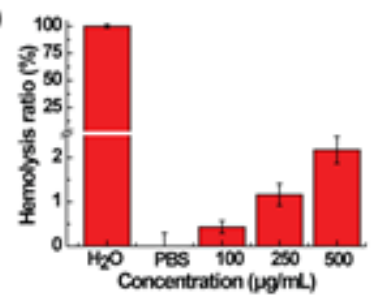

(b)
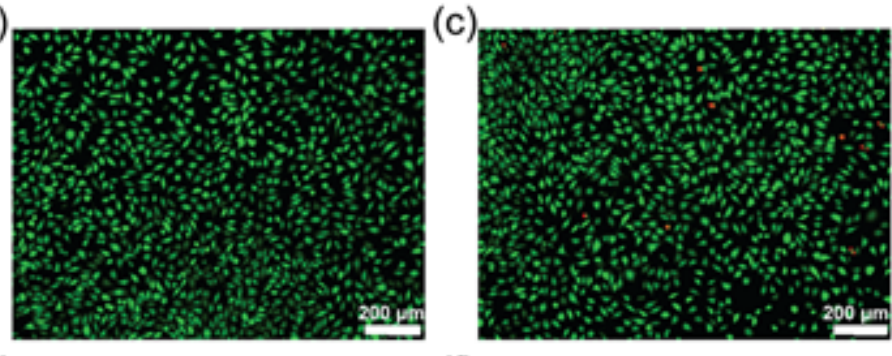

(e)
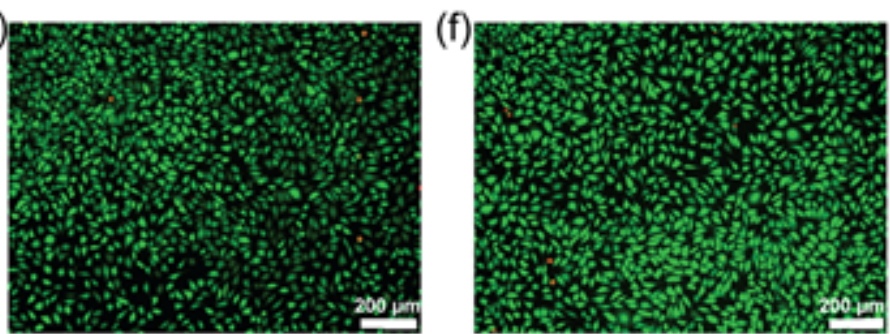

(h)

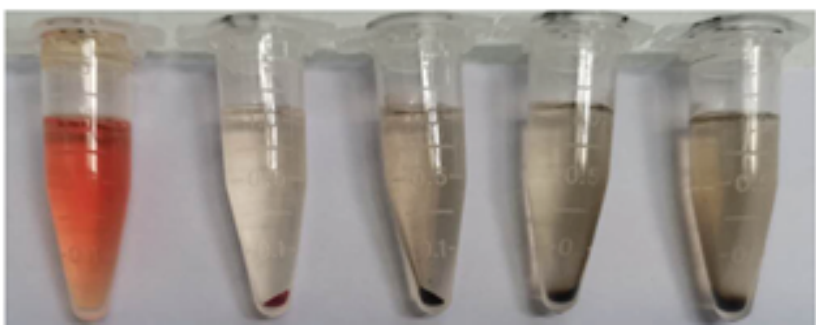

Figure 4

(a) L929 cells viabilities after cultured with different concentrations of IrO2@MSN@PDA-BSA(Ce6); (b-f) the photographs of Live/Dead staining relevant to (a); (g) hemolytic assay of IrO2@MSN@PDA-BSA(Ce6); (h) the photographic images relevant to $(\mathrm{g})$.

(a)

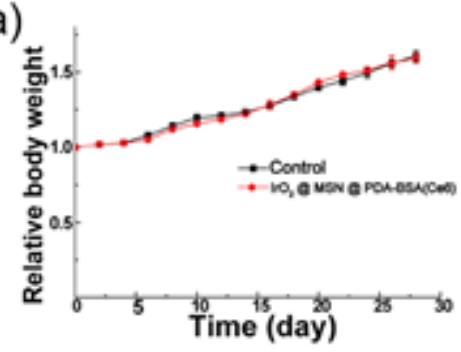

(b)

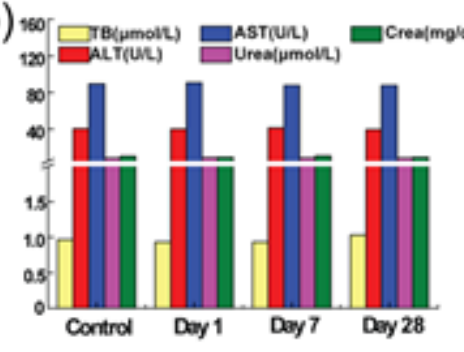

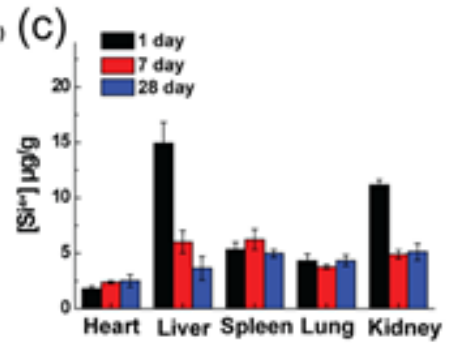

Kidney

(d)
$\bar{\vdots}$
ò
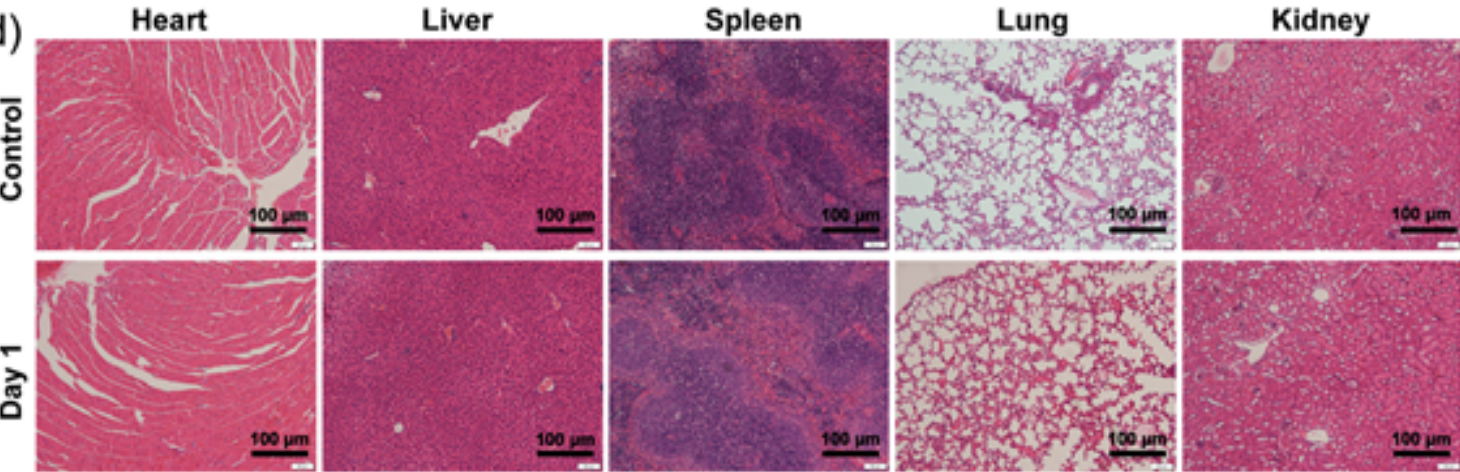

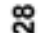
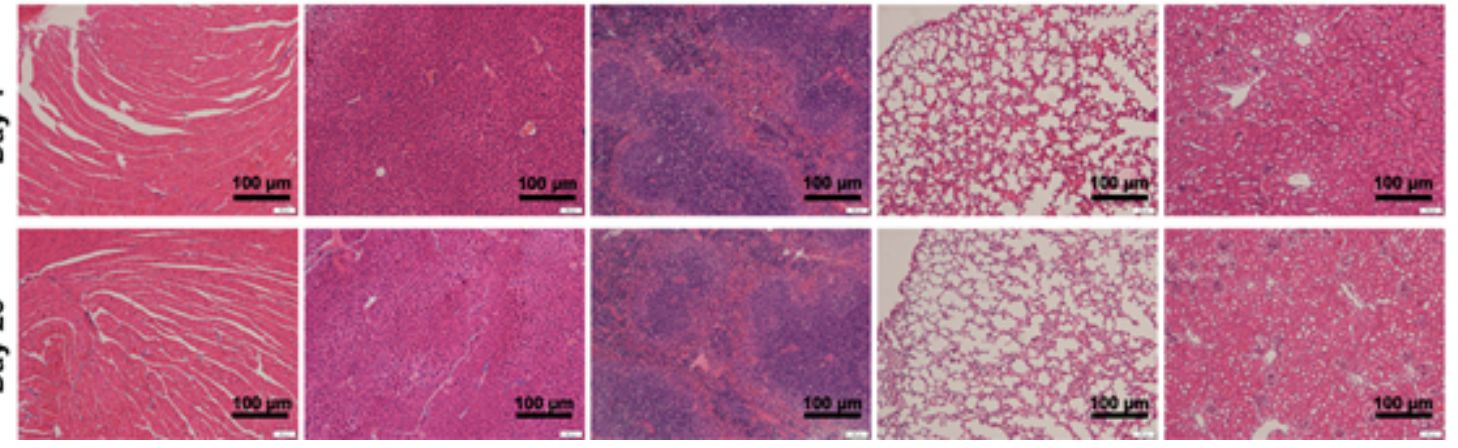


\section{Figure 5}

(a) Relative body weight of KM mice treated with saline or IrO2@MSN@PDA-BSA(Ce6) NPs (1 mg/ mL);

(b) blood biochemistry parameters; (c) biodistribution of Si ions in major organs of KM mice; (d) H\&E staining of the major organs of KM mice treated with saline (control) or IrO2@MSN@PDA-BSA(Ce6) NPs.

(a)

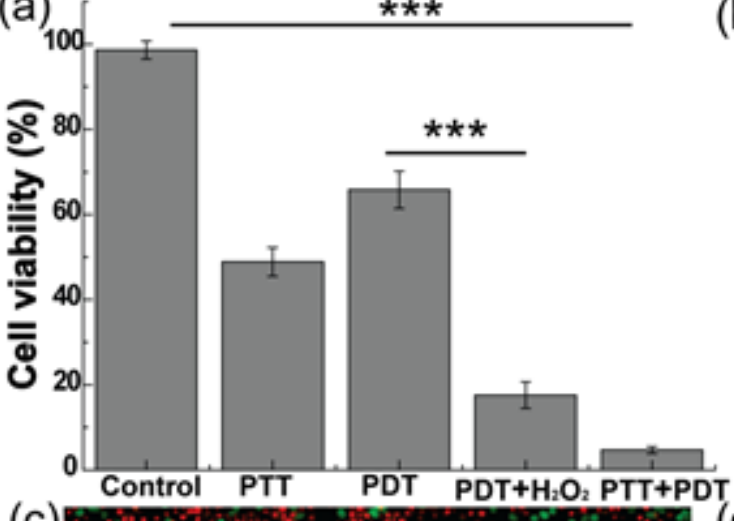

(c)

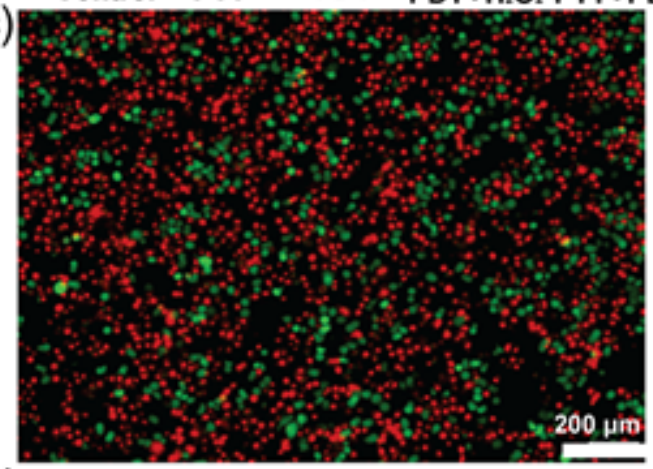

(e)

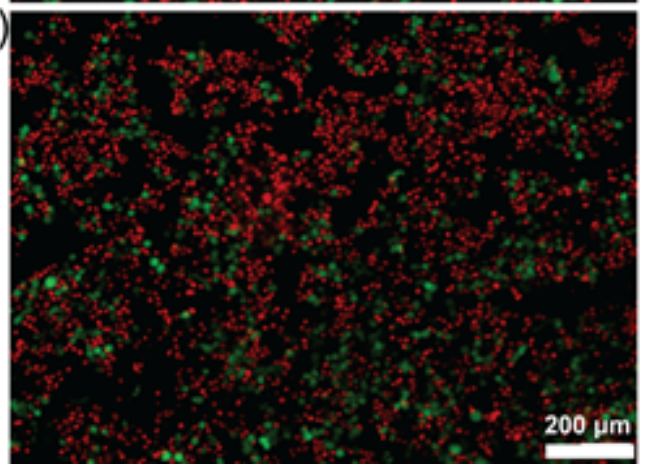

(b)

(d)
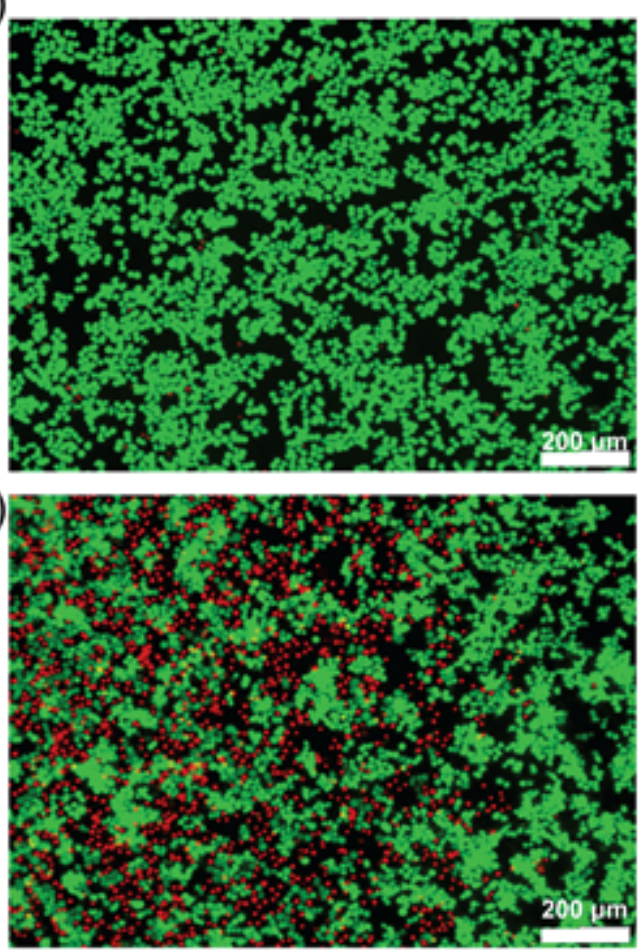

(f)

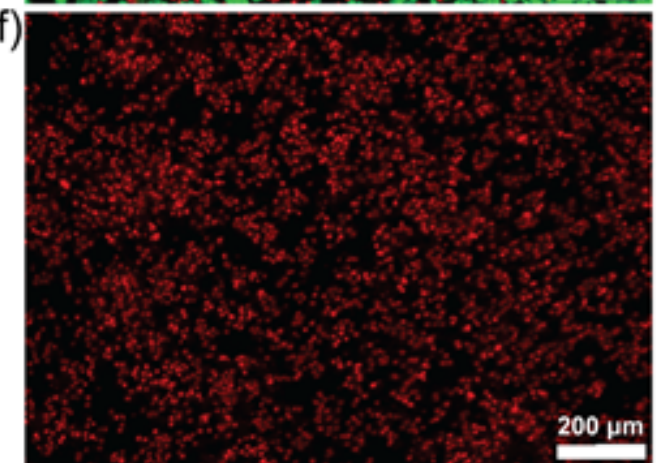

Figure 6

(a) HT29 cell viability after different treatments as noted; (b-f) the corresponding Live/Dead stained HT29 cells morphology (b: control; c: PTT; d: PDT; e: PDT + H2O2; f: PTT + PDT. 
(a)

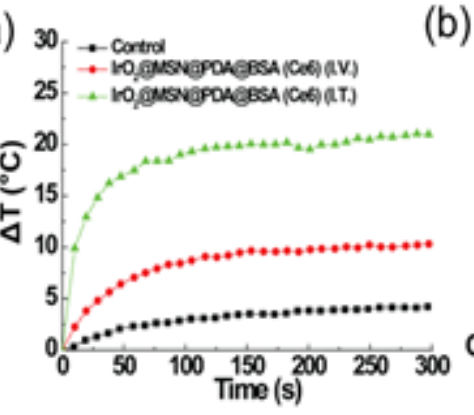

(b)

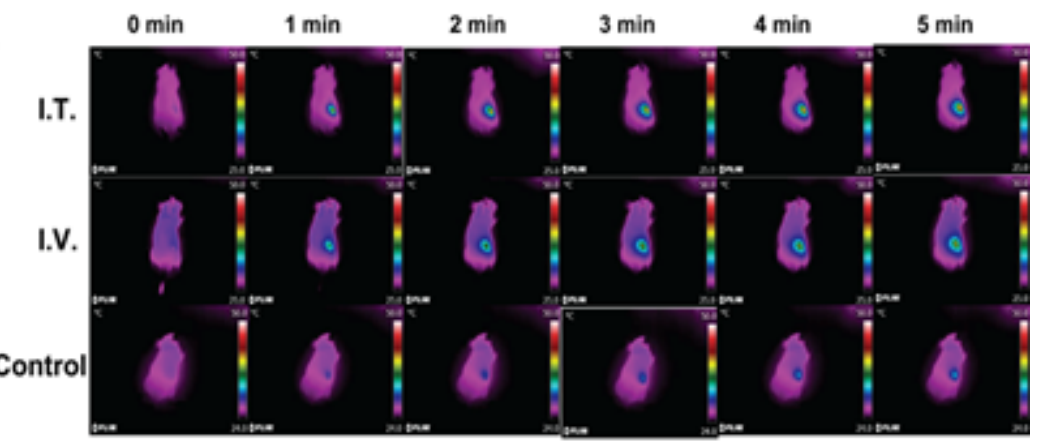

(c)

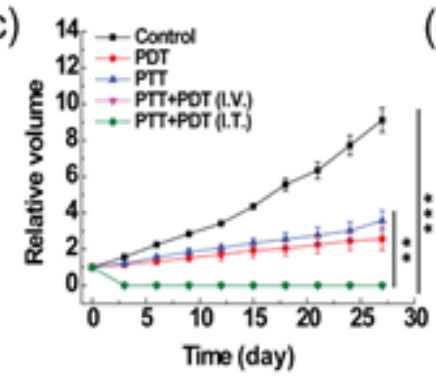

(d)

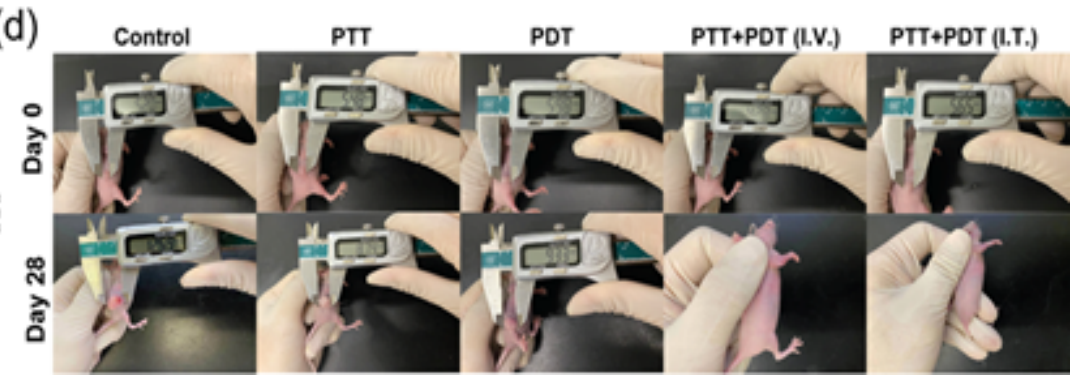

Figure 7

(a) The tumor temperature under NIR laser irradiation; (b) the corresponding thermal images of mice of panel (a); (c) relative tumor volume change curves of mice after different treatments as noted; (d) pictures of mice at days 0 and 28 of panel (c).

\section{Supplementary Files}

This is a list of supplementary files associated with this preprint. Click to download.

- Scheme01.png

- Supportinformation.docx 